\title{
Estudio histopatológico de 19 biopsias cutáneas de pacientes con sida e histoplasmosis diseminada
}

\author{
Gerzaín Rodríguez ${ }^{1}$, Adriana Motta ${ }^{2}$, Nelly Ordóñez ${ }^{3}$ \\ 1 Laboratorio de Patología, Instituto Nacional de Salud; Departamento de Patología, Facultad de Medicina, \\ Universidad Nacional de Colombia; Bogotá, D.C., Colombia. \\ ${ }^{2}$ Facultad de Medicina, Universidad El Bosque; Hospital Simón Bolívar, Bogotá, D.C., Colombia. \\ ${ }^{3}$ Laboratorio de Patología, Instituto Nacional de Salud, Bogotá, D.C., Colombia.
}

La histoplasmosis diseminada (HD) compromete la piel y la mucosa oronasofaríngea con alta frecuencia. Entre 1.800 enfermos con sida, 19 presentaron HD, todos con compromiso cutáneo o mucocutáneo. Las lesiones cutáneas fueron máculas, pápulas umbilicadas o escamocostrosas, nódulos y úlceras, en tanto que $42 \%$ de los pacientes presentaron ulceras orales. Las biopsias mostraron dermatitis perivasculares superficiales y profundas, nodulares y difusas, foliculitis pustulosa o vasculitis con PMN y leucocitoclasia, con cantidades variables del hongo, fagocitado por macrófagos. En 5 biopsias, Histoplasma capsulatum se vió dentro de los nervios cutáneos que estaban rodeados de inflamación variable o tenían perinervio desflecado y estaban invadidos por macrófagos con el hongo. Los principales diagnósticos diferenciales histológicos son: vasculitis leucocitoclásica, criptococosis, aftas, paracoccidioidomicosis y leishmaniasis difusa. Los clínicos, laboratoristas y patólogos deben tener en mente la HD en toda úlcera oral o erupción máculo-papular cutánea de pacientes con sida, pues el diagnóstico rápido de la micosis conduce a un tratamiento oportuno y eficaz, que controla la enfermedad. La biopsia es un procedimiento de diagnóstico rápido, seguro y confiable. $H$. capsulatum es capaz de invadir los nervios cutáneos.

Palabras clave: histoplasmosis diseminada, histoplasmosis y sida, histoplasmosis cutánea.

Histopathological study of 19 cutaneous biopsies from aids and disseminated histoplasmosis patients

Disseminated histoplasmosis (DH) frequently affects the skin and oropharyngeal tissues. Among 1,800 aids patients, 19 had $\mathrm{DH}$, all with cutaneous or mucocutaneous lesions. The skin showed macules, umbilicated crusty and scaly papules, nodules and ulcers, while $42 \%$ of the DH patients had oropharyngeal ulcers. Skin biopsies showed a variety of inflammatory patterns such as superficial and deep perivascular and nodular and diffuse dermatitis, pustular folliculitis and small vessel vasculitis with leucocytoclastic PMN. In five patients, cutaneous nerves were surrounded by the inflammatory reaction and numerous fungi within macrophages or Schwann cells were seen within the endoneural and perineural tissues. The main differential diagnoses were leucocytoclastic vasculitis, cryptococosis, mucosal aftae, paracoccidioidomycosis and diffuse cutaneous leishmaniasis. Clinicians, laboratory workers and pathologists should be aware of DH in HIV+ patients with maculo-papular cutaneous rash or mouth ulcers, since a prompt diagnosis allows a treatment to control the disease. Skin biopsy of these lesions is a rapid, safe and reliable method of diagnosis. $H$. capsulatum has the ability to penetrate into cutaneous nerves in some of these patients.

Key words: disseminated histoplasmosis, aids and histoplasmosis, cutaneous histoplasmosis. 
La histoplasmosis diseminada es una enfermedad 1 multisistémica con expresión clínica variable, fulminante, aguda, subaguda o crónica, en la cual Histoplasma capsulatum se comporta como germen oportunista. Cuando la causa de la inmunosupresión es el sida, la piel se compromete con una frecuencia tres veces mayor que cuando el factor que predispone para desarrollar la HD es otro (1). En Argentina, la afección mucocutánea en HD y sida ocurre en el $90 \%$ de los casos $(2,3)$. En Colombia, se han demostrado lesiones mucocutáneas en el $56 \%$ de estos pacientes (4). En este trabajo presentamos el estudio histopatológico de 19 biopsias de piel con lesiones de HD, que ocurrieron en pacientes con sida, estudiados en el Hospital Simón Bolívar y el Instituto Nacional de Salud de Bogotá entre 1992 y 1999. Las características clínicas y de laboratorio, el tratamiento y la evolución de estos enfermos se presentan en otro lugar (5).

\section{Materiales y métodos}

En el estudio de las lesiones cutáneas de 1.800 pacientes HIV positivos o con sida, atendidos en el Hospital Simón Bolívar, se encontraron 19 biopsias de piel en las cuales se estableció el diagnóstico de histoplasmosis. Los enfermos presentaban máculas, pápulas, pústulas, pápulovesículas o nódulos, localizados en el rostro o generalizados, así como úlceras cutáneas o de la mucosa oral de difícil diagnóstico clínico, interpretadas como reacciones medicamentosas, prúrigo, sífilis secundaria o úlceras de etiología desconocida (5). De manera característica, las lesiones comenzaron como máculas y en pocos días aumentaron en número y tamaño, originando pápulas o nódulos y, a veces, úlceras (5). Estas últimas predominaron en la cavidad oral. Siete pacientes presentaron úlceras del paladar, los labios y la lengua, además de sus lesiones cutáneas, y sólo uno tuvo como manifestación solitaria una úlcera lingual (5).

Las biopsias fueron sacabocados de $4 \mathrm{~mm}$ de diámetro y de 3 a $5 \mathrm{~mm}$ de profundidad, que se

\footnotetext{
Correspondencia:

G. Rodríguez, apartado aéreo 80334, Bogotá, D.C., Colombia; fax: 2223055 y 2220194.

grodriguez@hemagogus.ins.gov.co
}

Recibido: 09/01/01; aceptado: 09/02/01 fijaron en formol neutro al $10 \% \mathrm{y}$, luego del proceso usual, se sometieron a cortes seriados que se colorearon con hematoxilina-eosina ( $\mathrm{HE})$, ácido peryódico de Shiff (PAS) y plata-metenamina (Grocott) contrastada con HE, con eosina o con verde brillante (6).

\section{Resultados}

Las biopsias demostraron histoplasmosis cutánea, que usualmente no se sospechaba clínicamente, y condujeron al diagnóstico de sida en dos pacientes (5).

Las biopsias demostraron diferentes patrones: las máculas correspondieron a dermatitis perivasculares superficiales y profundas con infiltrados linfohistiocitarios discretos, con pocos hongos, cuyo diagnóstico puede pasar desapercibido sin las coloraciones de PAS y Grocott (figuras 1-3). Algunas pápulas de 2 pacientes mostraron infiltrados dérmicos hemorrágicos con necrosis fibrinoide de pequeños vasos, focal y discreta, con macrófagos y PMN con importante leucocitoclasia, lo que condujo al diagnóstico de vasculitis leucocitoclásica en el estudio inicial del tejido con coloración de HE. No obstante, con las coloraciones de PAS y Grocott se identificó $H$. capsulatum, lo cual llevó al diagnóstico correcto (figuras 4-6).

Las pústulas se asociaron con compromiso folicular, que fue frecuente y se debió a la eliminación transfolicular de neutrófilos y macrófagos cargados con el hongo, que originaron escamocostras y pústulas en el infundíbulo piloso (figuras 7-10). En estas pústulas fue posible demostrar el hongo en el examen directo, teñido con Giemsa (figura 11).

Algunas pápulas y nódulos correspondieron a dermatitis difusa con predominio de macrófagos vacuolados, repletos de hongos (figuras 12-14). Otras células del infiltrado fueron polimorfonucleares, sin formación de abscesos dérmicos, linfocitos y cantidad variable, usualmente escasa, de plasmocitos. La necrosis fue focal, con leucocitoclasia y en dos biopsias comprometió y destruyó algunos acrosiringios.

El hongo se identificó claramente con la HE, con su halo característico, y su pared se mostró muy bien con el PAS, una tinción general muy útil 

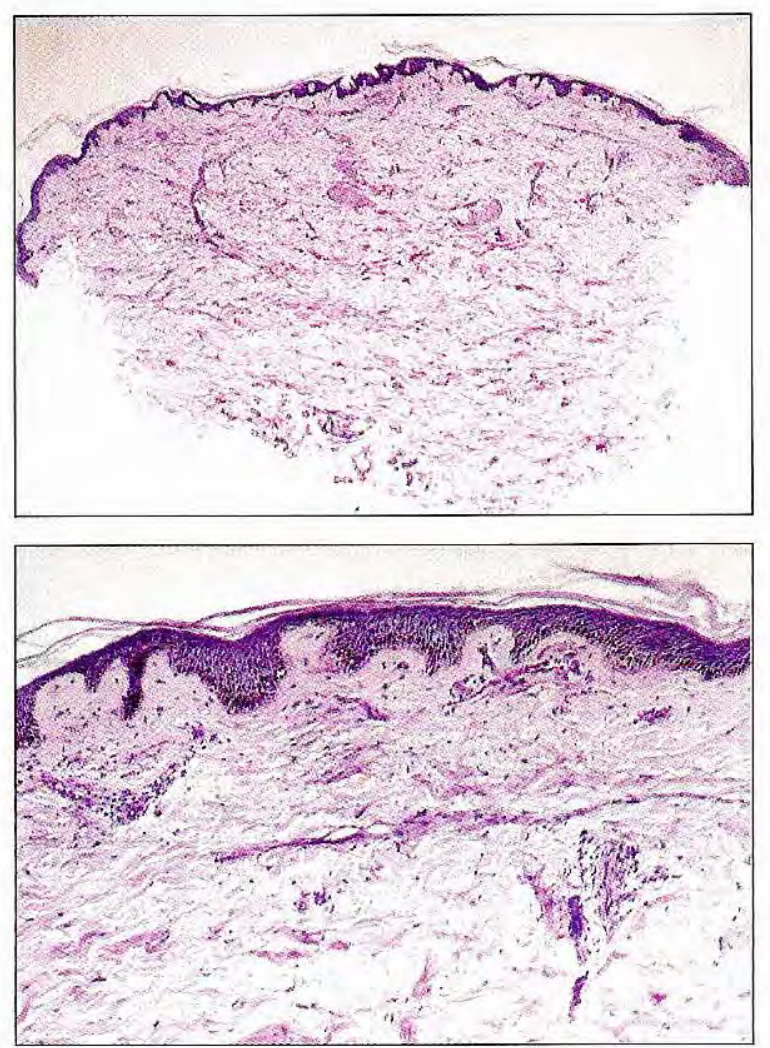

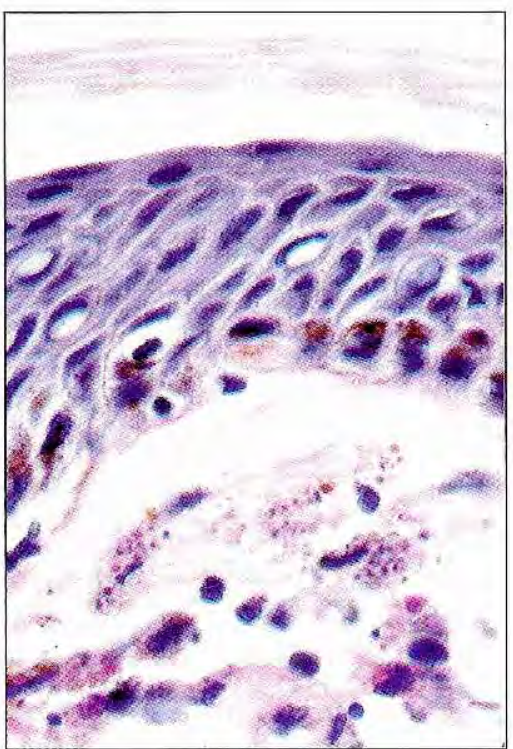

Figuras 1-3. En la imagen panorámica de la biopsia de una mácula (figura 1) se ve una tenue dermatitis perivascular superficial y profunda. La figura 2 muestra infiltrado linfohistiocitario alrededor del plejo vascular superficial y la figura 3 demuestra abundantes levaduras de $H$. capsulatum fagocitados por macrófagos en una papila dérmica. PAS. Figura 1: 25X; figura 2: 125X; figura 3: 1.000X.
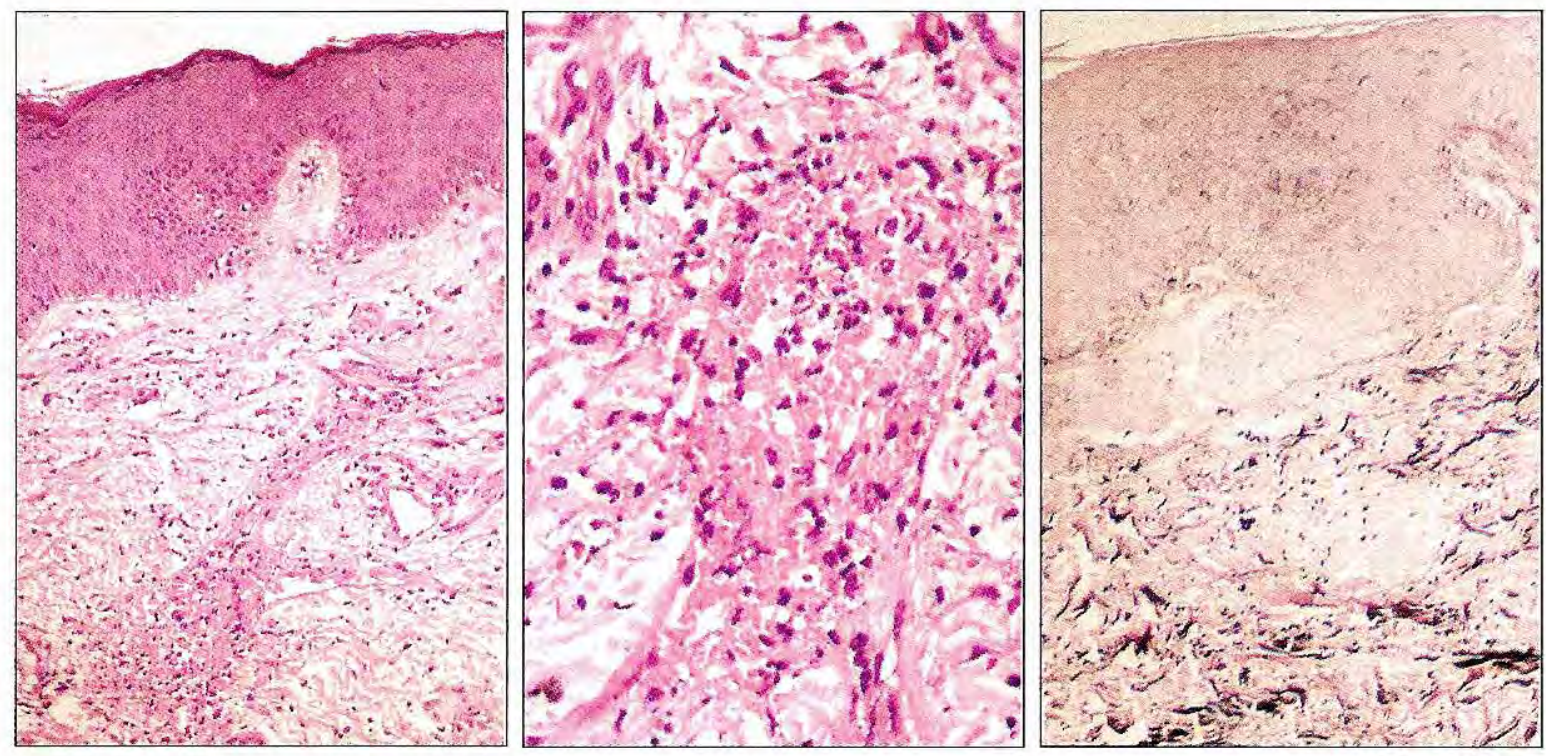

Figuras 4-6. La figura 4 muestra necrosis fibrinoide e infiltrado linfohistiocitario que sigue un trayecto vascular. La hemorragia, el material fibrinoide y la leucocitoclasia se ven claramente en la figura 5. Es fácil que el hongo pase desapercibido en esta lesión. La coloración del área correspondiente en el corte seriado, teñido con Grocott, demuestra $H$. capsulatum en la figura 6, que aparece como puntos argirófilos negros. Figura 4: 160X; figura 5: 400X; figura 6: 160X. 

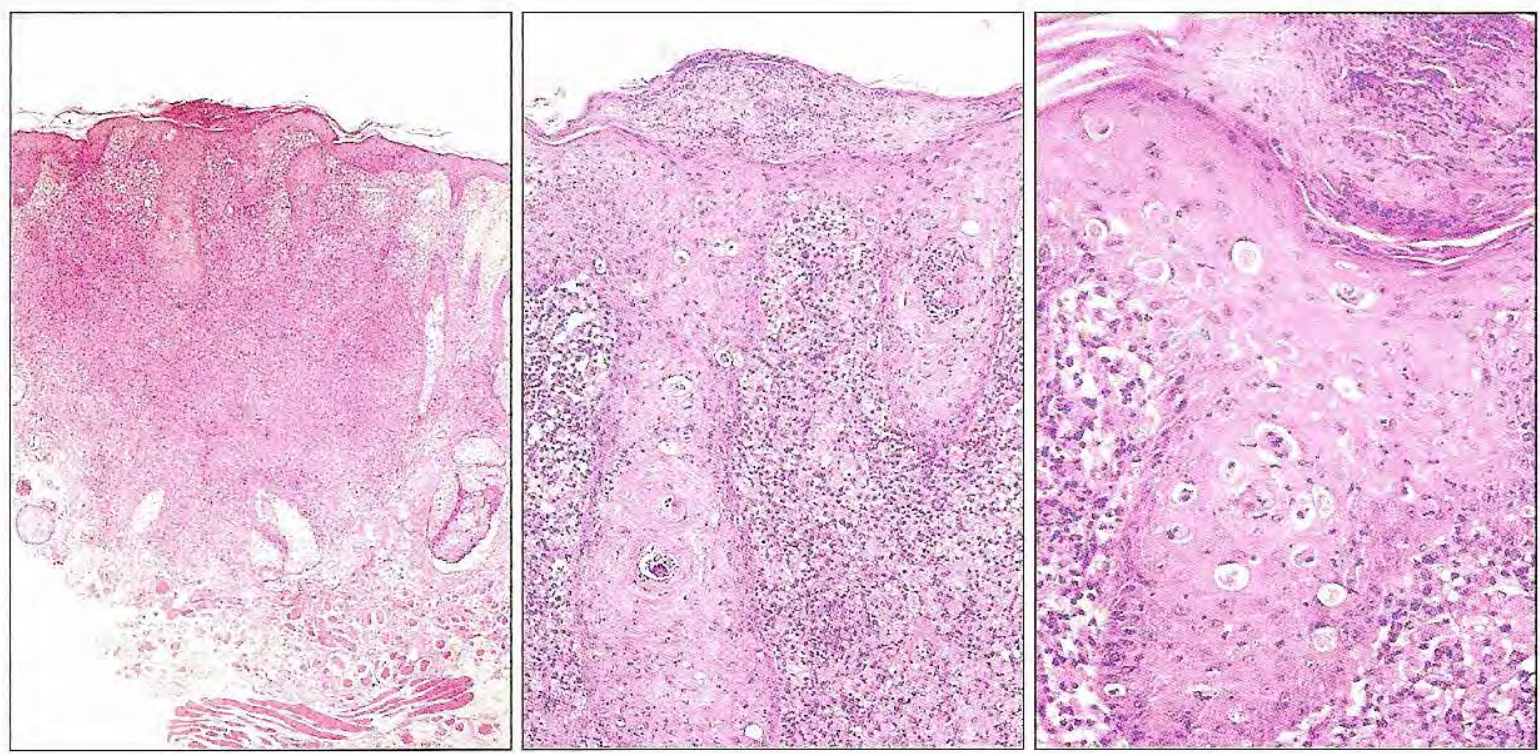

Figuras 7-9. La imagen panorámica (figura 7) muestra una dermatitis difusa que engloba varios folículos pilosos y corresponde a una pápula. En las figuras 8 y 9 , se ven dos infundíbulos pilosos rodeados por el infiltrado que los permea y forma una pústula sobre el ostium folicular. Las células claras dentro del infundíbulo en la figura 9 son macrófagos que contienen el hongo. Figura 7: 25X; figura 8: 100X; figura 9: 200X.

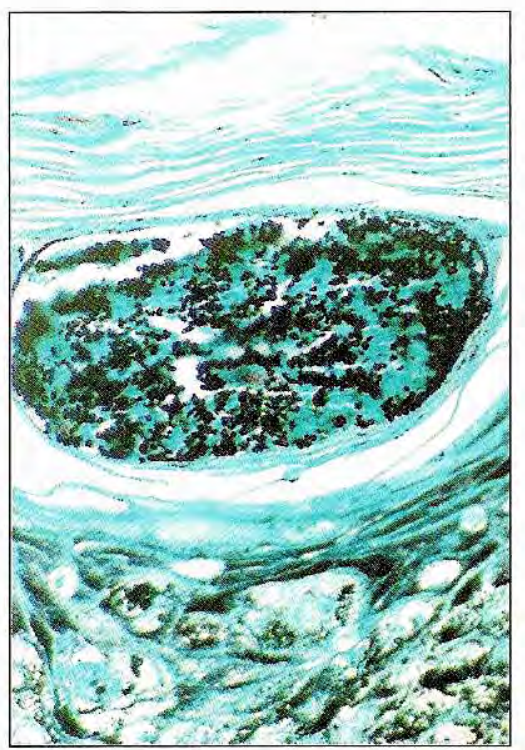

Figura 10. En el corte seriado teñido con Grocott y contrastado con verde brillante, se observan abundantes levaduras de $H$. capsulatum dentro de la pústula folicular, $500 X$.

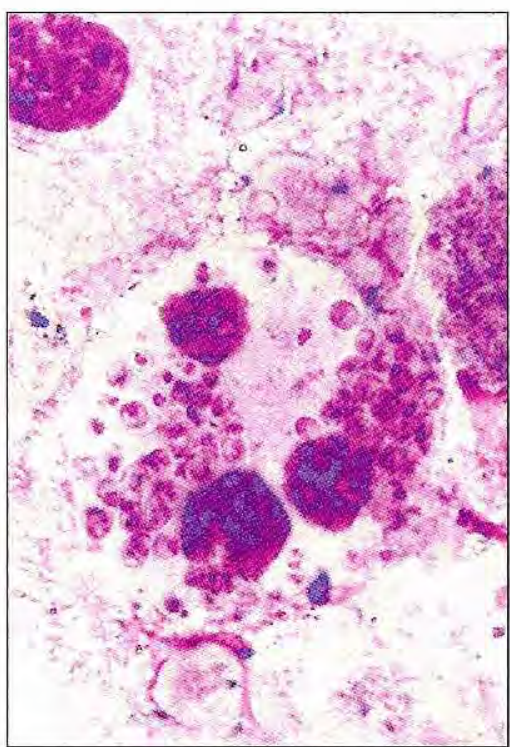

Figura 11. Si se hace un frotis de la pústula mostrada en la figura 10 , el hongo se demuestra en pocos minutos, como se ve aquí, dentro de un macrófago. Giemsa, 1.200X. 

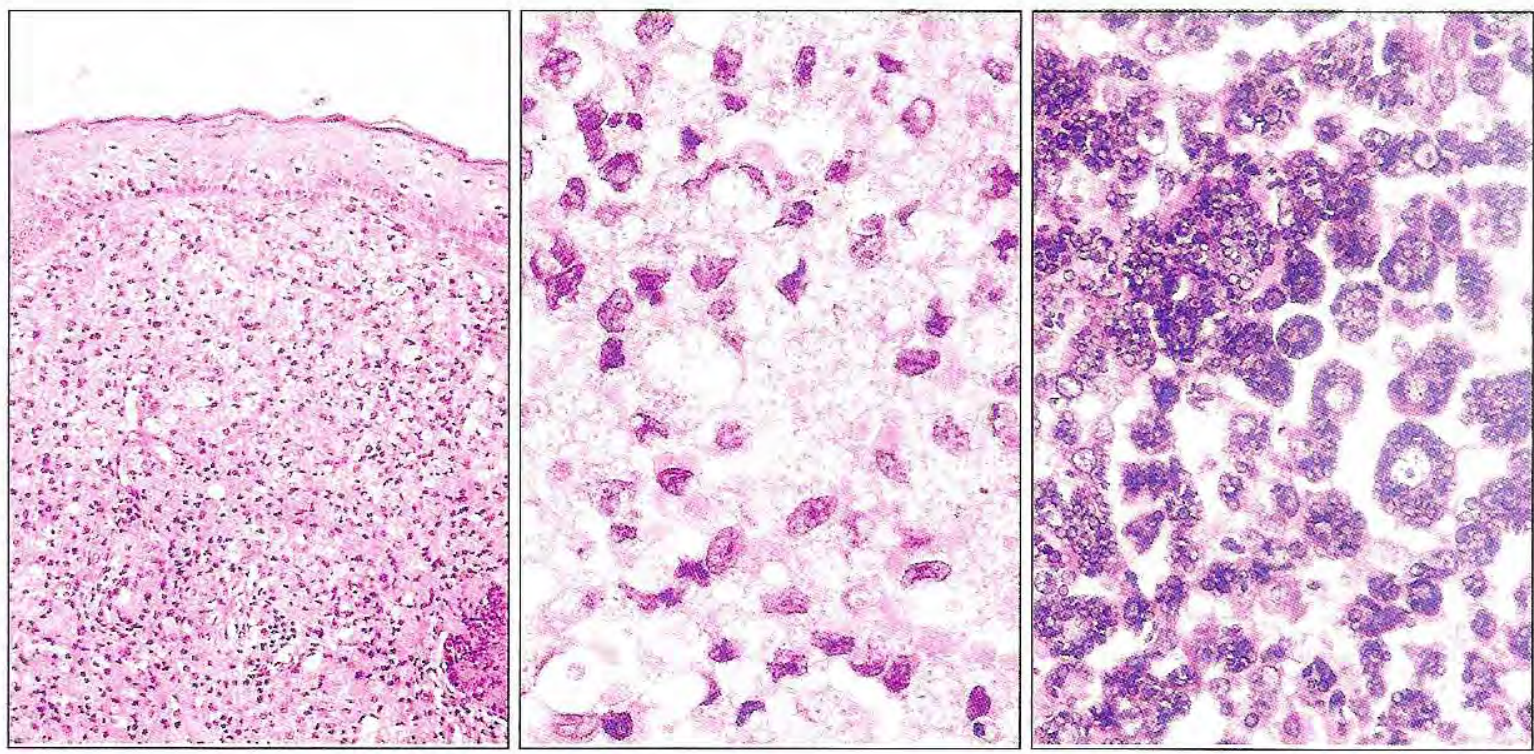

Figuras 12-14. Dermatitis difusa con un granuloma macrofágico con varios fagocitos vacuolados. Contienen miríadas de hongos que constan de un núcleo y citoplasma centrales, teñidos de azul en la HE, separados por un halo claro de su pared celular. Esta se tiñe de negro con la coloración de plata-metenamina (Grocott), contrastada con HE (figura 14). Figura 12: 200X; figura 13: 1.000X; figura 14: 800X.

cuando el germen es escaso. La tinción de platametenamina tiñe todo el hongo y revela con mejor claridad su presencia. El hongo es intracelular pero ocasionalmente se vió en el intersticio, en las áreas de necrosis. Fue llamativo observarlo en las biopsias de cinco pacientes dentro de nervios cutáneos de la dermis media y profunda, que estaban permeados desde el perinervio por algunos polimorfonucleares y macrófagos. EI hongo se vió allí dentro de estos fagocitos y dentro de algunas células de Schwann (figuras 15-18).

\section{Discusión}

H. capsulatum es un hongo intracelular, parásito de los macrófagos, que también prospera extracelularmente, por ejemplo, en las zonas de necrosis donde lo observamos libre entre los haces colágenos. También se ha visto en las vegetaciones fibrinoides, acelulares, de las endocarditis histoplasmósicas (7). Debe ser combatido por la inmunidad celular a través de una respuesta de tipo $\mathrm{TH} 1(8,9)$. Como esta fase de la respuesta inmune es la más afectada en el sida, la aparición de HD es posible y frecuente en estos enfermos (8), que tienen mayor riesgo de desarrollar la HD cuando el recuento de sus LT está por debajo de $75 / \mathrm{mm}^{3}$ (10).

La HD es una enfermedad grave en la que el hongo predomina en órganos ricos en macrófagos, por lo cual es común que curse con adenopatías, hepatoesplenomegalia y con leucopenia, anemia y plaquetopenia, secundarias al compromiso de la médula ósea. El comprómiso cutáneo y mucoso es variable, pero muy importante por su visualización fácil y porque puede someterse a diagnóstico rápido por diferentes métodos. El cultivo del hongo es mucho más sensible cuando se hace de raspados cutáneos que cuando se hace de otros especímenes, por ejemplo de secreciones bronquiales (4). Las lesiones mucosas, oronasofaríngeas, han sido frecuentes antes y después del sida $(2-4,7,8,11)$. En Colombia, estas lesiones mucocutáneas se han presentado en más de la mitad de los casos (4). En los pacientes con sida de este estudio, la HD ocurrió en el $1 \%$ de los enfermos y el compromiso cutáneo en el $100 \%$ de ellos. Como este criterio definía la inclusión de pacientes, es comprensible que la frecuencia de HD entre nosotros sea mayor. 
El diagnóstico histológico de HD es fácil e inmediato en las lesiones nodulares y papulosas, que corresponden a dermatitis difusas muy ricas en hongos, los cuales se identifican desde la HE por su centro basófilo y el halo que los rodea. El PAS tiñe claramente el hongo, sobre todo su pared y el Grocott lo tiñe de negro. El contraste de esta impregnación argéntica con $\mathrm{HE}$ permite reconocer las demás estructuras cutáneas con precisión. La coloración de PAS, tan familiar para todos los
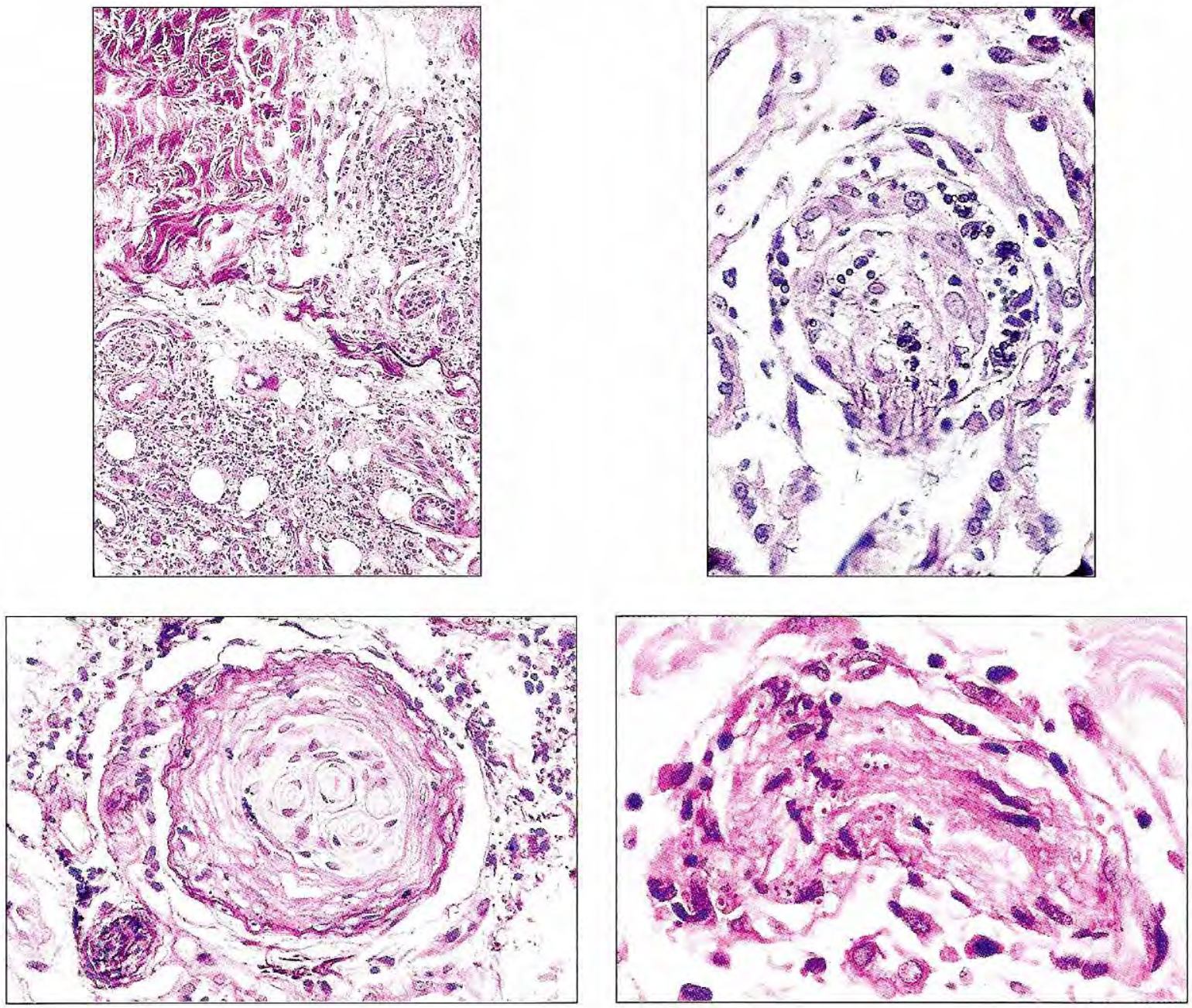

Figuras 15-18. Compromiso de los nervios cutáneos: la figura 15 muestra un infiltrado inflamatorio de la dermis profunda que engloba los anexos sudoríparos y los filetes nerviosos; éstos contienen abundantes levaduras de $H$. capsulatum. En la figura 16 , se ve uno de estos filetes cutáneos con el perinervio desflecado y con abundantes hongos peri y endoneurales. En la figura 17, hay abundantes hongos en el perinervio y en las células endoneurales de esta terminación nerviosa de Vatter-Paccini. Figuras 16-18: Grocott contrastado con HE. En la figura 18, teñida con PAS, el nervio cutáneo está rodeado por poca inflamación; contiene abundantes levaduras de $H$. capsulatum, algunas probablemente dentro de las células de Schwann. Figura 15: 200X; figura 16: 640X; figura 17: 500X; figura18: 1.000X. 
de macrófagos y a la formación de pústulas en el infundíbulo piloso. Este hallazgo orienta en la realización de frotes directos que revelan el hongo al micólogo o bacteriólogo, quien usualmente tiñe estos frotes con Giemsa $(2,4,12)$. Es necesario que este examen de diagnóstico rápido, en pocos minutos $u$ horas, sea confirmado con otros estudios como la biopsia o el cultivo, por cuanto estos enfermos tienen también amplia colonización bacteriana y por Malassezia sp. de su piel, con los que, según nuestra experiencia, se puede confundir el hongo $H$. capsulatum.

Los hallazgos histopatológicos de estas biopsias condujeron a una rápida familiarización de los médicos dermatólogos con la HD y a que la sospecharan con buena sensibilidad clínica en los últimos casos, en dos de los cuales se han realizado exámenes directos con demostración confiable del hongo. Los tratamientos se han prescrito alrededor de una semana después de la consulta y, a veces, antes.

La afección de los nervios cutáneos por el hongo (13) es un hallazgo novedoso que hemos reconfirmado en dos nuevos casos recientes. El hongo penetra al endonervio por invasión de los macrófagos que rompen el perinervio, o por vía sanguínea, como lo sugiere su presencia dentro de filetes nerviosos no rodeados por mayor componente inflamatorio (13). Hemos estudiado las vísceras de pocos pacientes muertos por HD y sida y no hemos visto invasión neural por el hongo en el intestino, ganglios linfáticos, bazo e hígado, pero ésta es una pesquisa llamativa para los patólogos. La presencia de H. capsulatumen los nervios origina, a su vez, otros interrogantes: ¿produce síntomas?, ¿es una fuente para recidivas?, ¿penetran los antimicósicos al nervio?

Los diagnósticos diferenciales, algunos propios de nuestro medio, son la vasculitis neutrofílica leucocitoclásica, la criptococosis cutánea asociada al sida, la leishmaniasis visceral y difusa, la esporotricosis y, en las lesiones ulceradas de la boca, las aftas y la paracoccidioidomicosis.

En la vasculitis neutrofílica leucocitoclásica, el hongo pasa desapercibido en los focos de necrosis, confundiéndose con los fragmentos nucleares $(1,12)$. La práctica rutinaria de la coloración de PAS en toda biopsia de un paciente HIV positivo permite demostrar con facilidad el hongo en estas zonas de vasculitis y en el resto del infiltrado.

En la criptococosis cutánea asociada con el sida, las lesiones macroscópicas son pápulas o nódulos de centro deprimido y la histopatología muestra enorme número de Cryptococcus neoformans dentro de los macrófagos, con cápsulas claras, gruesas, sin estructura a la HE, que se tiñen con el azul alciano o con el mucicarmín $(6,9)$, único hongo con esta característica. La impresión general de la biopsia es la de una lesión cutánea repleta de material mucoide claro y sin inflamación (14), pero muy rica en hongos. Se han descrito lesiones cutáneas mixtas con $C$. neoformans e H. capsulatum $(15,16)$ en las que estas diferentes técnicas histológicas serían útiles para demostrar la presencia de ambos hongos. Los cultivos son esenciales para la confirmación definitiva del diagnóstico y para aclarar los casos difíciles o de controversia. Un anticuerpo policlonal anti- $H$. capsulatum de uso reciente en nuestro laboratorio, demuestra muy bien las levaduras de $H$. capsulatum y no reacciona con $C$. neoformans.

La leishmaniasis visceral es el diagnóstico diferencial más importante de la histoplasmosis en los especímenes ganglionares, esplénicos o hepáticos, una diferenciación que es de naturaleza vital para el enfermo $(17,18)$. El cinetoplasto de la Leishmania es visible a la HE e identifica al microorganismo; el PAS y el Grocott tiñen a $H$. capsulatum y no a la leishmania. La leishmaniasis visceral no afecta la piel y, en nuestro medio, no se han descrito casos de dermatitis post-kalaazar, entidad que se presenta luego del tratamiento de la leishmaniasis visceral, en la cual se ven placas y nódulos cutáneos que pueden contener abundantes amastigotes. La leishmaniasis difusa cursa con pápulas y nódulos cutáneos, a veces voluminosos, que microscópicamente corresponden a granulomas macrofágicos muy ricos en amastigotes, con abundantes plasmocitos; las lesiones son cutáneas y no afectan las vísceras (19). Es necesario usar las técnicas histoquímicas enunciadas antes o visualizar el cinetoplasto para establecer la diferenciación adecuada con la histoplasmosis. Las técnicas inmunohisto- 
químicas, tanto para demostrar los amastigotes (17) como para teñir el hongo, son otros recursos que puede emplear el patólogo. La microscopia electrónica distingue claramente los dos organismos (18).

Algunas úlceras cutáneas produjeron la impresión clínica de esporotricosis, entidad que se excluye rápidamente al hacer el examen histológico, por la abundancia de levaduras de $H$. capsulatum y por el predominio de un granuloma rico en macrófagos vacuolados, a diferencia de los granulomas mixtos con cuerpos asteroides de la esporotricosis (20).

Las úlceras de la boca que podrían confundirse con histoplasmosis, tanto clínica como histológicamente, son las aftas, las úlceras producidas por virus herpes y las debidas a la paracoccidioidomicosis. En las aftas, hay ulceración sin hiperplasia epitelial e infiltrados mixtos de linfocitos y PMN que comprometen el epitelio, el corion y los vasos profundos. No se demuestran gérmenes ni con la $\mathrm{HE}$, ni con coloraciones especiales. En las úlceras herpéticas, se observa acantolisis y células uni o multinucleadas con inclusiones virales intranucleares, especialmente abundantes en los enfermos con sida; también es posible practicar técnicas de inmunohistoquímica para demostrar la presencia viral. La paracoccidioidomicosis produce hiperplasia pseudoepiteliomatosa e inflamación difusa con microabscesos. El hongo, con su multigemación característica, se ve fácilmente con la coloración de HE y, aún mucho mejor, con las coloraciones de PAS y Grocott, fagocitado en las células gigantes.

La HD crónica puede cursar con granulomas ricos en células gigantes, epitelioides y linfocitos, con pocos o ningún hongo demostrable en la biopsia, porque el paciente todavía conserva una buena inmunidad celular. Esto ocurrió en uno de nuestros pacientes, que sólo presentó una úlcera crónica de la lengua, de la cual se aisló $H$. capsulatum por cultivo (5). En su evolución natural, la histoplasmosis en estos pacientes HIV positivos se diseminará rápidamente y el diagnóstico se hace obvio en biopsias posteriores $(5,9)$. Estos enfermos deben tratarse como si tuvieran HD (5).
En conclusión, la HD es una enfermedad oportunista en los enfermos con sida; cursa con lesiones de la piel, la lengua y la orofaringe, producidas por el hongo. Estas lesiones son de fácil acceso en el estudio clínico y de laboratorio; por esa razón, deben ser bien conocidas por los clínicos, bacteriólogos, microbiólogos y patólogos. La biopsia es un procedimiento rápido y específico de diagnóstico. El diagnóstico oportuno conduce a un tratamiento preventivo, que controla la histoplasmosis y mejora sustancialmente la calidad de vida de estos enfermos.

\section{Referencias}

1. Cohen PR, Held J, Grossman M, Ross M, Silvers D. Disseminated histoplasmosis present as an ulcerated verrucous plaque in a human immunodeficiency virusinfected man. Report of a case possibly involving human to human transmission of histoplasmosis. Int J Dermatol 1991;30:104-7.

2. Starck F, Lasa MF, Bermejo A, Leiro V, Pizzariello G. Histoplasmosis y SIDA. Estudio sobre 13 pacientes con compromiso cutáneo, mucoso y cutáneo-mucoso. Dermatol Argent 1998;3:223-8.

3. Negroni R, Taborda A, Benetucci J, Bouza J, Macias J. Manifestaciones cutáneo-mucosas de la histoplasmosis en pacientes con SIDA. Rev Argent Dermatol 1990;71:71-8

4. Tobón A, Franco L, Correa A, Bedoya F, Ortega J, Soto M, et al. La histoplasmosis en el adulto. Bases para su diagnóstico. Acta Méd Colomb 1997;22:277-84.

5. Motta A, Rodríguez G, Ordóñez N. Histoplasmosis diseminada con compromiso cutáneo en pacientes con SIDA. Acta Méd Colomb 2001;26:9-15.

6. Prophet E, Mills B, Arrington J, Sobin L. Grocott's methenamine silver nitrate method for fungi (GMS). En: Prophet E, Mills B, Arrington J, Sobin L, editors. Laboratory methods in histotechnology. Washington, D.C.: Armed Forces Institute of Pathology; 1992. p.225.

7. Goodwin RA, Shapiro Jl, Thurman GH, Thurman S, Des Prez R. Disseminated histoplasmosis: clinical and pathologic correlations. Medicine 1980;59:1-33.

8. Wheat J. Endemic mycoses in AIDS: a clinical review. Clin Microb Rev 1995;8:146-59.

9. Dávila SC, Chapadeiro E. Características histopatológicas e imunohistoquímicas das lesões cutâneas e da mucosa oral na histoplasmose disseminada de portadores da síndrome da imunodeficiência adquirida (AIDS). Rev Soc Bras Med Trop 1998;31:539-47.

10. Hajjeh R. Disseminated histoplasmosis in persons infected with human immunodeficiency virus. Clin Infect Dis 1995;21:S108-10. 
11. Negroni R, Arechavala A, Robles AM. Histoplasmosis diseminada crónica como afección oportunista. Med Cut ILA 1987; 15:377-83.

12. Eidbo J, Sánchez R, Tschen J, Ellner K. Cutaneous manifestations of histoplasmosis in the acquired immune deficiency syndrome. Am J Surg Pathol 1993;17:110-6.

13. Rodríguez G, Ordóñez N, Motta A. Histoplasma capsulatum var. capsulatum within cutaneous nerves in patients with disseminated histoplasmosis and AIDS. Br J Dermatol 2001;144:205-7.

14. Ackerman AB. Histologic diagnosis of inflammatory skin diseases. Second edition. Philadelphia: Williams \& Wilkins; 1997. p.222.

15. Arango M, Cano LA, De Bedout C, Estrada S, Gómez I, Franco L, et al. Histoplasmosis y criptococosis diseminada en pacientes con el síndrome de inmunodeficiencia adquirida (SIDA). Acta Méd Colomb 1990;15:84-91.

16. Myers S, Kamino $\boldsymbol{H}$. Cutaneous cryptococcosis and histoplasmosis coinfection in a patient with AIDS. J Am Acad Dermatol 1996;34:898-900.

17. Rodríguez G. Leishmaniasis y sistema linfático. Acta Méd Colomb 2000;25:199-203.

18. Rodríguez G, Ricaurte O, de Naranjo JP. Granulomas infecciosos del hígado. Biomédica 1989;9:32-57.

19. Rodríguez G. Leishmaniasis difusa. Rev Asoc Colomb Dermatol 2000;8:33-40.

20. Rodríguez G, Sarmiento L. The asteroid bodies of sporotrichosis. Am J Dermatopathol 1998;20:246-9. 